\title{
Contact Lens Use Patterns, Behavior and Knowledge Among University Students in Thailand
}

This article was published in the following Dove Press journal: Clinical Ophthalmology

\author{
Chantaka Supiyaphun' \\ Passara Jongkhajornpong (D) ${ }^{2}$ \\ 'Department of Ophthalmology, Faculty of \\ Medicine, Vajira Hospital, Navamindradhiraj \\ University, Bangkok, Thailand; ${ }^{2}$ Department \\ of Ophthalmology, Faculty of Medicine, \\ Ramathibodi Hospital, Mahidol University, \\ Bangkok, Thailand
}

Purpose: Little is known about contact lens (CL) use in young generation. This study aimed to investigate the patterns, behavior and knowledge of CL wear and care in Thai university students. Methods: A cross-sectional study using online questionnaires was conducted during July 2019 to February 2020 in two Rajabhat universities, Bangkok, Thailand. Participant characteristics, CL information, knowledge and behaviors were collected. Factors associated with poor behaviors and CL-related corneal ulcers were analyzed using logistic regression. Results: Of 493 students participating in the survey, 336 students (66.78\%) were current CL users and completed the questionnaires. Mean age was $19.2 \pm 1.4$ years with female predominance $(80.36 \%)$. All students wore soft CL with a major replacement schedule of monthly disposable (90.18\%). Good CL wear and care behaviors were found in 190 students (56.55\%). The most common poor CL behavior and poor CL knowledge were CL overuse $(44.64 \%)$ and sleeping with lenses $(31.85 \%)$, respectively. There were no correlations between behaviors and knowledge $(r=0.03)$. Purchasing lens from internet, wearing experience over one year, and long wear duration ( $>12$ hours) were significantly associated with poor CL behavior. Male gender and swimming with lens were significantly associated with history of corneal ulcers.

Conclusion: The study pointed out a low compliance of CL wear and care in Thai university students. Good CL practices, awareness of CL-related complications and purchasing place should be carefully informed and regularly stressed to minimize preventable visual damage in young population.

Keywords: contact lens, behavior, knowledge, university students, Thailand

\section{Introduction}

Contact lenses (CL) are used by millions of people globally with an increased trend. The recent survey from US Centers for Disease Control and Prevention (CDC) estimated that the prevalence of CL wearers in US has risen from 40.9 million in 2015 to 45 million in $2019 .{ }^{1}$ Main purpose of wearing CL is vision correction., ${ }^{2,3}$ CL provide several advantages to wearers compared to spectacles in terms of convenience, wider visual field and improved personality. ${ }^{4}$ However, poor compliance of CL wear and care can lead to serious ocular complications which cause permanent visual loss. ${ }^{5}$ A review found that noncompliance rate in CL wearers was high, ranging from $50 \%$ to $91 \%{ }^{6}$ Corneal ulcer is one of the most severe complications in CL wearers. ${ }^{7}$ Lots of evidence demonstrated a strong association between poor CL compliance and the increased risk of corneal ulcers. ${ }^{5,8-11}$ Common risk behaviors in CL wearers are identified as overnight use, sharing lens, swimming with lens, and inadequate CL care. ${ }^{5,11,12}$
Correspondence: Passara Jongkhajornpong Department of Ophthalmology, Faculty of Medicine, Ramathibodi Hospital, Mahidol University, 270 Thanon Rama VI, Thung Phaya Thai, Ratchathewi, Bangkok, 10400 Tel +662 2012729

Email passaraj@yahoo.com
Clinical Ophthalmology 2021:15 1249-1258 
Teenagers and young adults are found to have less contact lens compliance. ${ }^{13,14}$ Previous studies revealed that people in this age group had higher corneal infiltrative events (CIE) $)^{13-15}$ as well as microbial keratitis compared to older adults. ${ }^{5}$ University students are considered the major population in this age group. We experience a trend of increasing CL-related complications in Thai young adults. This phenomenon has also been observed in Singapore and Australia. ${ }^{16,17}$ To date, little is known about CL wear and care status in Thailand, especially among university students. This survey aims to investigate the pattern, knowledge and behaviors of CL wear and care in Thai university students. We also evaluate risk factors which are possibly associated with poor CL behaviors and CL-related corneal ulcers. The results from this study would help raise awareness of having good CL compliance in young people community and act as a primer for improving $\mathrm{CL}$ education policy in the future.

\section{Methods}

This study was a cross-sectional survey conducted during July 2019 to February 2020 in two Rajabhat universities consisting of Sunandha Rajabhat and Suan Dusit University, Bangkok, Thailand. Rajabhat Universities are a part of the university system in Thailand which originated from a teacher college system and resembles a polytechnic institute format to serve the rest of Thailand's educational needs with over 38 different campuses across the country. Since the upgrade to university status, both universities in the system have a student population of over 5000 students from six main faculties including Faculty of Education, Faculty of Science and Technology, Faculty of Humanities and Social Sciences, Faculty of Industrial Technology, Faculty of Fine Arts, and Faculty of Management Science. This study protocol was approved by the Research Ethics Committee of Navamindradhiraj University and Ramathibodi Hospital, Mahidol University in accordance with the tenets of Declaration of Helsinki.

An online survey on knowledge and behavior of CL using self-administered questionnaire was introduced to all university students by university staffs and via school advertising media. Students who wore CL and were willing to participate in the survey could access the electronic survey through the QR code scanning on the designated mobile Google Form. Electronic informed consent was obtained from every participant before starting survey. We excluded participants who were not a current CL user within one year and did not complete all key questions in the survey.

The questionnaire was in Thai language adapted from a previous study. ${ }^{18}$ It was composed of three sections; the first section was demographic data (ie, gender, age, studying faculty, and type of refractive error) and CL information (ie, type of CL, reasons for using CL, places of purchasing lenses, average wearing time and duration of wearing contact lens). The second section asked about CL behaviors. There were nine items including hand washing, sleeping overnight with lens, swimming with lens, sharing lens, follow lens replacing schedule, cleaning lens and lens case, and history of CL-related ocular complications. In the last item, the participants were also asked about how they managed themselves when complications occurred and how frequently they went for eye check-up. The third section contained eight items to inquire about the knowledge of CL wear and care, and CL-related ocular complications, similar to the second section (the second and third sections of the questionnaire in English are available in Appendix). Responses of seven yes/no questions in second and third sections were scored (one score per each correct response) and summarized to determine total behavior and knowledge scores. Participants who correctly answered at least six from seven items $(>80 \%)$ in the second and third section were classified as having good behavior and good knowledge, respectively.

\section{Statistical Analysis}

Descriptive analysis was performed to describe characteristics of participants. Continuous variables were reported in means (standard deviation, SD) or median (range), where appropriate. Categorical variables were reported in frequency and percentage.

The correlation between knowledge and behavior was analyzed using Spearman's rank correlation for individual item and Pearson's correlation for total score. Univariate logistic regression analysis was used to identify the risk factors associated with poor CL behaviors and history of CL-related corneal ulcers. Then factors which were significant at $p$ level of less than 0.1 in the univariate analysis, were subsequently included in the multivariate analysis. Odd ratios (OR) from univariate analysis and adjusted OR from multivariate analysis along with $95 \%$ confidence intervals (CI) were calculated for each factor. All analyses were calculated using STATA version 16 (StataCorp, College Station, TX, USA). P value of less than 0.05 was considered statistically significant. 


\section{Results}

\section{Participants Characteristics}

Of 503 students who scanned QR code, 493 students (98.01\%) obtained electronic informed consent to participate in the survey. Three-hundred and thirty-six students (66.78\%) were current CL users and completed the survey questionnaires. Mean age was 19.2 (SD 1.4) years with female predominance. Of 336 students, 272 students (80.95\%) studied at Suan Sunandha Rajabhat University and 64 students (19.05\%) studied at Suan Dusit University as shown in Table 1. Most participants were from Faculty of Management Science, Faculty of Humanities and Social Science and Faculty of Innovation and Management. Two hundred and ninety students $(83.31 \%)$ wore CL due to refractive error correction, while 46 students (13.69\%) used $\mathrm{CL}$ for cosmetic purposes. Median refractive error was $-2.75 \mathrm{D}$ (ranged from -8.00 to $0.00 \mathrm{D}$ ). All students used soft CL. The replacement schedules were monthly (90.18\%). Major reasons for choosing particular CL were eye comfort $(82.44 \%)$, CL brand $(14.58 \%)$, and cost (2.98\%). Duna (Top Charoen; Nonthaburi, Thailand), was the most common CL brand (35.42\%) followed by Maxim (Maxim inter-corporation LTD; Bangkok, Thailand, 13.39\%) and Bausch \& Lomb (17.86\%). Other bands reported were Kitty Kawaii, Acuvue and other brands of colored CL (eg, Lollipop, Pretty Doll, Dreamcolor, and Olens). Students purchased their lens from an optical shop (66.07\%), flea market (14.29\%) and from the internet $(13.10 \%)$. The participants mostly wore lens on an average of 5 days per week, 8-12 hours per day.

\section{Contact Lens Behavior}

Most participants (280 students, 83.33\%) wash hands every time before inserting or removing CL. Other participants usually washed hand (42 students, 12.50\%), sometimes washed hands (9 students, 2.68\%) and five students (1.49\%) never washed hands. Ninety-nine students $(29.46 \%)$ ever slept overnight with lens. Fifteen students (4.46\%) ever shared lens with friends. One hundred and eighty-six students (55.36\%) replaced lens according to the manufacturer recommendation. Eighty-six students $(25.60 \%)$ had ever swum with lens. Fiftyone students (15.81\%) used tap water for cleaning or rinsing lens. Two hundred and sixty-three students $(78.27 \%)$ used fresh lens solution every day. Most students (90.18\%) changed storage cases every one to three months. One hundred ninety students $(56.55 \%)$ had good CL wear and care behaviors.

\section{Contact Lens Knowledge}

Two hundred and twenty-nine students (68.15\%) had awareness of sleeping overnight with lens. Almost all participants had awareness of sharing lens with friends (95.54\%), swimming with lens $(91.07 \%)$, and using tap water for cleaning or rinsing lens (96.13\%). Two hundred ninety-five students $(87.80 \%)$ were aware of lens replacement as recommendation. Having knowledge of using fresh lens solution every day and changing lens case every one to three months were reported in 298 students $(88.69 \%)$ and 255 students $(75.89 \%)$, respectively. Two hundred sixty-four students $(78.57 \%)$ had good knowledge in $\mathrm{CL}$ wear and care.

\section{Relationship Between Contact Lens Behavior and Knowledge}

Knowledge and behavior were not correlated in all questions, except for sharing lens with friends $(r=1.00$, $\mathrm{p}$ value $<0.001)$. Spearman's rank correlations between knowledge and behavior ranged from -0.04 to 1.00 , see Table 2. According to the total score, mean behavior scores and knowledge scores were 5 (SD 1) and 6 (SD 1), respectively. There was no correlation between CL behavior and knowledge $(r=0.03, p=0.655)$.

\section{Factors Associated with Poor Contact Lens Wear and Care Behaviors}

In univariate analysis, purchasing lenses from internet significantly associated with poor CL behavior with the OR $(95 \% \mathrm{CI})$ of $2.47(1.27,4.78)$ compared purchasing lenses from optical shop. Students who had experience of wearing CL more than 1 year were 1.98 times (95\% CI $1.18,3.33)$ likely to have poor CL behavior. Long wearing time per day ( $>12$ hours/day) and regular wearing $(>5$ days/week) were more likely to have poor CL behavior with the ORs $(95 \% \mathrm{CI})$ of $2.37(1.05,5.35)$ and $1.59(1.00$, 2.54), respectively, as Table 3. After multivariate adjustment, the remaining significant associated factors with poor CL behaviors included: purchasing from internet, wearing experience of more than 1 year and long wearing time per day with poor CL behaviors with the adjusted ORs $(95 \% \mathrm{CI})$ of $2.74(1.39,5.41), 1.82(1.04,3.18)$, and $2.56(1.07,6.13)$, respectively, see Table 3.

\section{Contact Lens-Related Ocular Complications and Eye Check-Up}

For CL-related complications, seventy-four students (22.02\%) had experienced ocular problems related to CL. 
Table I Demographics, Refractive Errors and Contact Lens Information of Participants $(\mathrm{N}=336)$

\begin{tabular}{|c|c|}
\hline Characteristics & Number (\%) \\
\hline Female & $270(80.36 \%)$ \\
\hline Age (mean $\pm S D$, years) & $19.2 \pm 1.4$ \\
\hline \multicolumn{2}{|l|}{ University } \\
\hline Suan Dusit & $64(19.05 \%)$ \\
\hline Suan Sunandha Rajabhat & $272(80.95 \%)$ \\
\hline \multicolumn{2}{|l|}{ Faculty } \\
\hline Management science & $142(42.26 \%)$ \\
\hline Humanities and social science & $78(23.21 \%)$ \\
\hline Innovation and management & $26(7.74 \%)$ \\
\hline Science and technology & $17(5.06 \%)$ \\
\hline Education & $14(4.17 \%)$ \\
\hline Fine arts & $14(4.17 \%)$ \\
\hline Others & 45 (13.39\%) \\
\hline Refractive error (median and range, D) & $-2.75(-8.00$ to 0.00$)$ \\
\hline Having astigmatism & $105(31.25 \%)$ \\
\hline \multicolumn{2}{|l|}{ Purpose of using contact lens } \\
\hline Refractive error correction & $290(83.31 \%)$ \\
\hline Cosmetic purposes & $46(13.69 \%)$ \\
\hline Contact lens experience (median and range, year) & $2.7(0.1$ to 7$)$ \\
\hline Soft contact lens & $336(100 \%)$ \\
\hline \multicolumn{2}{|l|}{ Replacement schedule } \\
\hline Daily & $22(6.55 \%)$ \\
\hline Bi-weekly & $6(1.79 \%)$ \\
\hline Monthly & $303(90.18 \%)$ \\
\hline \multicolumn{2}{|l|}{ Major reason for purchasing particular contact lens } \\
\hline Comfortable feeling & 277 (82.44\%) \\
\hline Contact lens brand & 49 (14.58\%) \\
\hline Cost & $10(2.98 \%)$ \\
\hline \multicolumn{2}{|l|}{ Contact lens brand } \\
\hline Duna & $119(35.42 \%)$ \\
\hline Bausch + Lomb & $60(17.86 \%)$ \\
\hline Maxim & 45 (13.39\%) \\
\hline Kitty Kawaii & 27 (8.04\%) \\
\hline Acuvue & $13(3.87 \%)$ \\
\hline Others & $28(8.33 \%)$ \\
\hline \multicolumn{2}{|l|}{ Place of purchase } \\
\hline Optical shop & $222(66.07 \%)$ \\
\hline Flea market & 48 (14.29\%) \\
\hline Internet & $44(13.10 \%)$ \\
\hline Department store & $13(3.87 \%)$ \\
\hline \multicolumn{2}{|l|}{ Lens wear duration per day } \\
\hline$<8$ hours/day & $93(27.68 \%)$ \\
\hline $8-12$ hours/day & $216(64.29 \%)$ \\
\hline$>12$ hours/day & 27 (8.04\%) \\
\hline Lens wear per week (mean $\pm S D$, days) & $4.7 \pm 1.6$ \\
\hline
\end{tabular}

(Continued)
Table I (Continued).

\begin{tabular}{|l|c|}
\hline Characteristics & Number (\%) \\
\hline Cleaning solution & \\
Multipurpose solution & $323(96.1 \%)$ \\
Normal saline solution & $8(2.38 \%)$ \\
Tap water & $3(0.89 \%)$ \\
\hline
\end{tabular}

Thirty-four students (10.12\%) had history of corneal ulcers. Fifty-three students (15.77\%) had other complications including red eye, dry eye and other unspecified problems, shown in Table 4. All students knew that CL wear could lead to ocular complications, however only $40.77 \%$ of students were aware of CL-related corneal ulcer. Eye irritation and dry eye were the most known complications. Other known complications included corneal abrasion and corneal neovascularization. If any ocular problems occurred during CL wear, most students $(81.25 \%)$ would take out their lens immediately and $24.49 \%$ of students would go see an ophthalmologist. Only 10 participants would continue wearing the lens without doing anything.

For eye check-up, 219 students (65.18\%) never underwent eye check-up with ophthalmologists or optometrists. Only 17 students (5.06\%) had eye check-up, see Table 4.

\section{Risk Factors Associated with Contact Lens-Related Corneal Ulcers}

From univariate analysis, wear and care behaviors including wash hands, sharing lens with friends, swimming with $\mathrm{CL}$ and using tap water to clean or rinse lens were significantly associated with history of having CL-related corneal ulcers with the OR $(95 \%$ CI $)$ of $0.37(0.17$, $0.80), 3.53$ (1.06, 11.76), 3.87 (1.87, 8.00), and 2.65 $(1.18,5.95)$, respectively. After multivariate analysis, male gender and swimming with lens were statistically significant association with history of corneal ulcers at the adjusted ORs of $2.78(1.20,6.42)$ and 3.44 (1.57, 7.55), see Table 5 .

\section{Discussion}

This current study comprehensively evaluated pattern of CL use, behaviors and knowledge in terms of CL wear, care, and CL-related complications in university students in Thailand. This survey pointed out inadequate CL wear and care behaviors in Radjabhat University system and 
Table 2 Behavior and Knowledge of Contact Lens Wear and Care of Participants $(\mathrm{N}=336)$

\begin{tabular}{|l|c|c|c|c|c|}
\hline \multirow{2}{*}{ Questions } & \multicolumn{2}{|c|}{ Behavior } & \multicolumn{2}{c|}{ Knowledge } & \multirow{2}{*}{ Correlation* (p value) } \\
\cline { 2 - 6 } & Yes & No & Yes & No & \\
\hline Sleeping overnight with lenses & $99(29.46 \%)$ & $237(70.54 \%)$ & $229(68.15 \%)$ & $107(31.85 \%)$ & $0.03(0.527)$ \\
Sharing lenses with friends & $15(4.46 \%)$ & $321(95.54 \%)$ & $321(95.54 \%)$ & $15(4.46 \%)$ & $1.00(<0.001)$ \\
Replace lenses as recommended & $186(55.36 \%)$ & $150(44.64 \%)$ & $295(87.80 \%)$ & $41(12.20 \%)$ & $0.05(0.367)$ \\
Swimming with contact lenses & $86(25.60 \%)$ & $250(74.4 \%)$ & $306(91.07 \%)$ & $30(8.93 \%)$ & $0.08(0.146)$ \\
Using tap water for cleaning/rinsing lenses & $51(15.81 \%)$ & $285(84.82 \%)$ & $323(96.13 \%)$ & $13(3.87 \%)$ & $0.001(0.983)$ \\
Using fresh lens solution every day & $263(78.27 \%)$ & $59(17.56 \%)$ & $298(88.69 \%)$ & $38(11.31 \%)$ & $-0.04(0.515)$ \\
Changing lens case every I-3 months & $303(90.18 \%)$ & $8(2.38 \%)$ & $255(75.89 \%)$ & $81(24.11 \%)$ & $-0.04(0.449)$ \\
\hline Average total score (mean, SD) & \multicolumn{2}{|c|}{$5(1)$} & & $6(1)$ & \\
\hline
\end{tabular}

Note: *Using Spearman's rank correlation for each question and Pearson correlation for average total score.

found that only $56.55 \%$ of students reported to have good $\mathrm{CL}$ wear and care behaviors. Although a majority of students (78.57\%) had good knowledge in CL wear and care, no significant correlation between behaviors and knowledge was observed. Top three poor behaviors were overused CL, sleeping with lenses and swimming with lenses. We hypothesized that overused CL might be influenced from a lack of funds in unemployed students, a lack of education by eye care providers, and a lack of awareness of bad consequences, similar to those key factors mentioned in the previous study. ${ }^{13}$ Young adults $(18-25$ years) have been shown to be less likely to wash their hands before applying their lens compared to older adults (26-33 years). ${ }^{13}$ We found that approximately one fifth of our students infrequently or never wash their hands before handling lenses.

Eight students reported not changing lens cases within three months. It has been demonstrated that several pathologic organisms, ie, free-living Acanthamoeba and Pseudomonas colonized on the surface of lenses and storage cases, thus CL can potentially act as a vector for corneal infection. ${ }^{19}$ Failure to replace or properly clean and store lens subsequently lead to the formation of biofilm which increases the risk of ocular infection. ${ }^{20}$ The lens case should be cleaned daily with fresh contact lens solution and allowed to air dry to reduce the chance of pathogen contamination, and should be replaced every 90 days. $^{21}$

Previously identified factors influencing on CL compliance included age, gender, education, socio-economic level and perceived threat of disease. ${ }^{2,13,22}$ Although we did not observe an association between gender and $\mathrm{CL}$ behavior, male students were about three times more likely to have a history of CL-related corneal ulcer compared to females. In this current study, purchasing lens from internet, wearing experience over one year, and long wear duration ( $>12$ hours per day) were significantly associated with poor CL behavior. Unauthorized providers are significantly less likely to instruct appropriate lens hygiene, which could lead to poor lens compliance and higher CLrelated complications. ${ }^{11,23}$ Purchasing CL from internet was found to be associated with inadequate CL behavior with an OR of 2.47. Our finding is in line with the previous study in Australia in which purchased lenses from internet increased risk of microbial keratitis which was possibly explained by inadequate CL care attitudes and behaviors. ${ }^{11}$ Radford et al reported that CL wearing experience was inversely associated with $\mathrm{CL}$ compliance. ${ }^{24}$ Therefore, regular revision of lens hygiene at after-care visits should be emphasized for maintaining high level of CL compliance.

It has been known that poor initial instruction or lack of re-instruction can lead to non-compliance in $\mathrm{CL}$ wearers. ${ }^{24}$ However, a lack of correlation between behavior and knowledge was found in our study, implying that knowledge alone is not sufficient to drive good CL compliance. Our findings corresponded with some previous reports in medical students. ${ }^{25,26}$ Apart from knowledge, proper motivation, good doctor-patients relationship and strong regulation are importantly contributed to successful health promotion. ${ }^{27,28}$ Moreover, previous evidence has also shown that risk taking personalities, ie, being aware of health hazards demonstrating risky behaviors regardless of the awareness, are strongly related to overall CL compliance score. ${ }^{29}$ Multi-factors could have an influence on behavior in CL wearers.

In terms of CL-related complications, corneal ulcer is considered as one of the most devastating complications 
Table 3 Association Between Gender and Contact Lens (CL) Pattern with Poor CL Behavior

\begin{tabular}{|c|c|c|c|c|c|c|c|}
\hline \multirow[t]{2}{*}{ Factors } & \multirow[t]{2}{*}{ Categories } & \multicolumn{2}{|c|}{ Contact Lens Behaviors } & \multicolumn{2}{|c|}{ Univariate Analysis } & \multicolumn{2}{|c|}{ Multivariate Analysis } \\
\hline & & Poor & Good & OR $(95 \% \mathrm{Cl})$ & $P$ value & $\begin{array}{c}\text { Adjusted OR } \\
(95 \% \mathrm{Cl})\end{array}$ & $\begin{array}{l}\text { Adjusted } \\
\text { p value }\end{array}$ \\
\hline Gender & $\begin{array}{l}\text { Male } \\
\text { Female }\end{array}$ & $\begin{array}{l}25(37.88 \%) \\
|2|(44.81 \%)\end{array}$ & $\begin{array}{l}41(62.12 \%) \\
149(55.19 \%)\end{array}$ & $0.75(0.43,1.30)$ & 0.309 & & \\
\hline Lens replacement schedule & $\begin{array}{c}\text { Monthly } \\
\text { Daily/bi-weekly }\end{array}$ & $\begin{array}{c}132(56.44 \%) \\
12(42.86 \%)\end{array}$ & $\begin{array}{l}171(56.44 \%) \\
16(57.14 \%)\end{array}$ & $1.03(0.47,2.25)$ & 0.942 & & \\
\hline Colored contact lenses & $\begin{array}{l}\text { Yes } \\
\text { No }\end{array}$ & $\begin{array}{l}27(49.09 \%) \\
100(42.19 \%)\end{array}$ & $\begin{array}{l}28(50.91 \%) \\
137(57.81 \%)\end{array}$ & $1.32(0.73,2.38)$ & 0.354 & & \\
\hline Purpose of wearing lenses & $\begin{array}{l}\text { Refractive correction } \\
\text { Cosmetic purposes }\end{array}$ & $\begin{array}{l}125(43.10 \%) \\
21(45.65 \%)\end{array}$ & $\begin{array}{l}165(56.90 \%) \\
25(54.35 \%)\end{array}$ & $0.90(0.48,1.68)$ & 0.746 & & \\
\hline Refractive errors & $\begin{array}{l}<-3.00 \mathrm{D} \text { (high myopia) } \\
\geq-3.00 \mathrm{D} \text { (low myopia) }\end{array}$ & $\begin{array}{l}52(50.49 \%) \\
94(40.34 \%)\end{array}$ & $\begin{array}{l}51(49.51 \%) \\
139(59.66 \%)\end{array}$ & I.5I $(0.94,2.40)$ & 0.084 & $1.36(0.83,2.23)$ & 0.227 \\
\hline Place of purchase & $\begin{array}{l}\text { Flea market } \\
\text { Internet } \\
\text { Optical shop }\end{array}$ & $\begin{array}{l}25(52.08 \%) \\
27(61.36 \%) \\
92(39.15 \%)\end{array}$ & $\begin{array}{l}23(47.92 \%) \\
17(38.64 \%) \\
143(60.85 \%)\end{array}$ & $\begin{array}{l}1.69(0.90,3.15) \\
2.47(1.27,4.78)\end{array}$ & $\begin{array}{c}0.099 \\
0.007^{*}\end{array}$ & $\begin{array}{l}1.83(0.96,3.48) \\
2.74(1.39,5.41)\end{array}$ & $\begin{array}{l}0.066 \\
0.004 *\end{array}$ \\
\hline Wearing experience & $\begin{array}{l}>\text { I year } \\
\leq I \text { year }\end{array}$ & $\begin{array}{l}119(47.60 \%) \\
27(31.40 \%)\end{array}$ & $\begin{array}{l}131(52.40 \%) \\
59(68.60 \%)\end{array}$ & $1.98(1.18,3.33)$ & $0.008^{*}$ & $1.82(1.04,3.18)$ & $0.035 *$ \\
\hline Lens wear duration per day & $\begin{array}{l}>12 \text { hours } \\
\leq 12 \text { hours }\end{array}$ & $\begin{array}{c}17(62.96 \%) \\
129(41.75 \%)\end{array}$ & $\begin{array}{l}10(37.04 \%) \\
17(62.96 \%)\end{array}$ & $2.37(1.05,5.35)$ & $0.037^{*}$ & $2.56(1.076 .13)$ & $0.035^{*}$ \\
\hline Lens wear per week & $\begin{array}{l}>5 \text { days } \\
\leq 5 \text { days }\end{array}$ & $\begin{array}{c}53(51.46 \%) \\
93(39.91)\end{array}$ & $\begin{array}{l}50(48.54 \%) \\
140(60.09 \%)\end{array}$ & $1.59(1.00,2.54)$ & $0.049 *$ & $1.38(0.84,2.26)$ & 0.197 \\
\hline
\end{tabular}

Note: *Statistical significance at $\mathrm{p}$ value $<0.05$.

Abbreviations: $\mathrm{Cl}$, confidence interval; $\mathrm{OR}$, odds ratio.

which can lead to permanent visual impairment. ${ }^{30}$ Our previous study reported that $17.65 \%$ of severe microbial keratitis were associated with CL uses during 2010 to $2016 .{ }^{31}$ This prevalence was reported as high as $43.9 \%$

Table 4 Contact Lens-Related Ocular Complications and Eye Check-Up $(\mathrm{N}=336)$

\begin{tabular}{|l|c|}
\hline History & N (\%) \\
\hline Contact lens-related ocular complications & \\
Corneal ulcers & $34(10.12 \%)$ \\
Other complications & $53(15.77 \%)$ \\
Red eye & $11(3.27 \%)$ \\
Dry eye & $6(1.78 \%)$ \\
Eye irritation & $2(0.59 \%)$ \\
Eye fatigue & $1(0.30 \%)$ \\
Unspecified & $32(9.52 \%)$ \\
\hline Eye check-up & \\
Before and after wearing & $17(5.06 \%)$ \\
Only before wearing & $78(23.21 \%)$ \\
Only after wearing & $22(6.55 \%)$ \\
Never & $219(65.18 \%)$ \\
\hline
\end{tabular}

in the developed countries. ${ }^{30}$ Sleeping overnight with lens, poor storage cases hygiene, method of CL purchase, and swimming with lens were the important risk factors for CL-related corneal ulcers. ${ }^{8,11,16,32,33}$ Sleeping with lenses was found in over a half of patients with corneal ulcers. ${ }^{30}$ We found a slightly increased risk of corneal ulcers in students with a history of corneal ulcer, but it was not statistically significant, unlike findings from previous study. ${ }^{11,34,35}$ This might be explained by the differences of study design, subject characteristics and definition of overnight wear among studies.

The current study demonstrates that swimming pool was significantly associated with a higher rate of a history of CL-related corneal ulcer, similar to previous study in Singapore. ${ }^{33}$ Approximately one fourth of our students had swum with their lenses before, which was similar to the report from Singapore $(32.8 \%),{ }^{36}$ but less than recent report from US, which found students swimming with lenses to be $62-75 \%$ with a peak at college age. ${ }^{13,36}$ This high rate might be a result of the unclear recommendation from different purchase points and lack 
Table 5 Association Between Type of Gender, Contact Lens, Risk Behaviors and History of Having Contact Lens-Related Corneal Ulcer in Participants

\begin{tabular}{|c|c|c|c|c|c|c|c|}
\hline \multirow[t]{2}{*}{ Factors } & \multirow[t]{2}{*}{ Categories } & \multicolumn{2}{|c|}{$\begin{array}{l}\text { History of Contact Lens- } \\
\text { Related Corneal Ulcer }\end{array}$} & \multicolumn{2}{|c|}{ Univariate Analysis } & \multicolumn{2}{|c|}{ Multivariate Analysis } \\
\hline & & Yes & No & OR $(95 \% \mathrm{Cl})$ & $P$ value & $\begin{array}{l}\text { Adjusted OR } \\
\quad(95 \% \mathrm{Cl})\end{array}$ & $\begin{array}{l}\text { Adjusted } \\
\text { P value }\end{array}$ \\
\hline Gender & $\begin{array}{l}\text { Male } \\
\text { Female }\end{array}$ & $\begin{array}{l}11(16.67 \%) \\
23(8.52 \%)\end{array}$ & $\begin{array}{l}55(83.33 \%) \\
247(91.48 \%)\end{array}$ & $2.15(0.99-4.66)$ & 0.053 & $2.78(1.20,6.42)$ & $0.017^{*}$ \\
\hline Contact lens replacement schedule & $\begin{array}{l}\text { I Month } \\
<\text { I Month }\end{array}$ & $\begin{array}{l}31(10.23 \%) \\
2(7.14 \%)\end{array}$ & $\begin{array}{l}272(89.77 \%) \\
26(92.86 \%)\end{array}$ & $1.48(0.33,6.54)$ & 0.586 & & \\
\hline Colored contact lenses & $\begin{array}{l}\text { Yes } \\
\text { No }\end{array}$ & $\begin{array}{l}7(12.73 \%) \\
23(9.70 \%)\end{array}$ & $\begin{array}{c}48(87.27 \%) \\
214(90.30 \%)\end{array}$ & $1.35(0.55,3.34)$ & 0.507 & & \\
\hline Place of purchase & $\begin{array}{l}\text { Flea market } \\
\text { Internet } \\
\text { Optical shop }\end{array}$ & $\begin{array}{l}5 \text { (10.42\%) } \\
7 \text { (15.91\%) } \\
21 \text { (8.94\%) }\end{array}$ & $\begin{array}{c}43(89.58 \%) \\
37(84.09 \%) \\
214(91.60 \%)\end{array}$ & $\begin{array}{l}1.18(0.42,3.31) \\
1.92(0.76,4.86)\end{array}$ & $\begin{array}{l}0.746 \\
0.164\end{array}$ & & \\
\hline $\begin{array}{l}\text { Washing hand before inserting/removing } \\
\text { lenses }\end{array}$ & $\begin{array}{l}\text { Yes } \\
\text { No }\end{array}$ & $\begin{array}{l}23(8.21 \%) \\
\text { II (19.64\%) }\end{array}$ & $\begin{array}{l}257(91.79 \%) \\
45(80.36 \%)\end{array}$ & $0.37(0.17,0.80)$ & $0.012^{*}$ & $0.5 \mathrm{I}(0.2 \mathrm{I}, \mathrm{I} .20)$ & 0.123 \\
\hline Sleeping overnight with lenses & $\begin{array}{l}\text { Yes } \\
\text { No }\end{array}$ & $\begin{array}{l}12(12.12 \%) \\
22(9.28 \%)\end{array}$ & $\begin{array}{l}87(87.88 \%) \\
215(90.72 \%)\end{array}$ & $1.35(0.64,2.84)$ & 0.433 & & \\
\hline Sharing lenses with friends & $\begin{array}{l}\text { Yes } \\
\text { No }\end{array}$ & $\begin{array}{l}4(26.67 \%) \\
30(9.35 \%)\end{array}$ & $\begin{array}{l}\text { II (73.33\%) } \\
291 \text { (90.65\%) }\end{array}$ & $\begin{array}{l}3.53(1.06 \\
11.76)\end{array}$ & $0.040 *$ & $2.09(0.57,7.71)$ & 0.268 \\
\hline Replacing lenses as recommended & $\begin{array}{l}\text { Yes } \\
\text { No }\end{array}$ & $\begin{array}{l}18(9.68 \%) \\
16(10.67 \%)\end{array}$ & $\begin{array}{l}168(90.32 \%) \\
134(89.33 \%)\end{array}$ & $0.90(0.44,1.83)$ & 0.765 & & \\
\hline Swimming with contact lenses & $\begin{array}{l}\text { Yes } \\
\text { No }\end{array}$ & $\begin{array}{l}18(20.93 \%) \\
16(6.40 \%)\end{array}$ & $\begin{array}{c}68(79.07 \%) \\
234(93.60 \%)\end{array}$ & $3.87(1.87,8.00)$ & $<0.001 *$ & $3.44(1.57,7.55)$ & $0.002^{*}$ \\
\hline Using tap water to clean/rinse lenses & $\begin{array}{l}\text { Yes } \\
\text { No }\end{array}$ & $\begin{array}{l}10(19.61 \%) \\
24(8.24 \%)\end{array}$ & $\begin{array}{l}4 \mid(80.39 \%) \\
26 \mid(91.58 \%)\end{array}$ & $2.65(1.18,5.95)$ & $0.018^{*}$ & $2.26(0.93,5.49)$ & 0.073 \\
\hline Using fresh lens solution every day & $\begin{array}{l}\text { Yes } \\
\text { No }\end{array}$ & $\begin{array}{l}24(9.13 \%) \\
9(15.25 \%)\end{array}$ & $\begin{array}{l}239(90.87 \%) \\
50(84.75 \%)\end{array}$ & $0.56(0.24,1.27)$ & 0.165 & & \\
\hline Changing lens case every I-3 months & $\begin{array}{l}\text { Yes } \\
\text { No }\end{array}$ & $\begin{array}{c}31(10.23 \%) \\
0(0 \%)\end{array}$ & $\begin{array}{l}272(89.77 \%) \\
8(100 \%)\end{array}$ & NA & NA & & \\
\hline
\end{tabular}

Note: *Statistical significance at $p$ value $<0.05$.

Abbreviations: $\mathrm{Cl}$, confidence interval; NA, not available; OR, odds ratio.

of reinforcement from eye care professionals. ${ }^{37}$ It has been shown that swimming in a chlorinated pool allows for accumulation of gram positive bacteria which were the same as those found from pool water, in the lens, regardless of lens materials. ${ }^{38}$ If one considers the benefits of $\mathrm{CL}$ wear during water activities outweigh the risk of complication, the use of daily disposable lenses with tight-fitting goggles and discarding lenses immediately after swimming episode may be a safer practice to minimize the risk of corneal infection. ${ }^{37,38}$ Pseudomonas aeruginosa is the most common pathogen detected in CL-related microbial keratitis. ${ }^{17,30}$ Interestingly, it has been detected in 524/ $7904(6.6 \%)$ waters examined in hot tubs, tap water, jacuzzis, swimming pool and bottled water. ${ }^{39}$
Fifty-one students (15.81\%) reported using tap water for cleaning or rinsing lenses. Domestic water can be a source of Acanthamoeba contamination. ${ }^{40}$ Nearly $85 \%$ of patients with Acanthamoeba keratitis, one of the most devastating forms of corneal ulcers, had a common risk factor of exposing lenses to water. ${ }^{41,42}$ Identical strains of free-living Acanthamoeba have been recovered from water supply, contact lens cases ${ }^{43}$ and cornea ${ }^{44}$ of patients with Acanthamoeba keratitis. Inappropriate water exposure during wear and care of $\mathrm{CL}$ can also lead to bacterial contamination. ${ }^{45}$ Exposure to any source of water while wearing CL are likely to increase the risk of infection. ${ }^{44}$ Unexposed lenses and storage cases to any kinds of water for a one month-period has been proven to eliminate Acanthamoeba contamination. ${ }^{46}$ 
Cosmetic CL becomes increase in trend especially in young generation in several countries ${ }^{23,47}$ including in Thailand. This might be resulted from commercial influences, attitude of good appearance, reasonable price and ease of purchase. Many cosmetic CL brands have been approved by Thai FDA, eg, Kitty Kawaii, Pretty Doll and Sweety Plus. We found 55 students (18.84\%) using colored cosmetic CL. Although some studies have pointed out the risk of infection in cosmetic CL wearers, ${ }^{23,47,48}$ we did not observe significant association between cosmetic colored CL and poor contact lens behaviors or CL-related corneal ulcers. The discrepancy compared to other studies may be due to the monitoring and approval of cosmetic CL from the Thai FDA. Most of students in our study wear Thai FDA approved colored CL with refractive error corrections (mean refractive errors of $-2.21 \mathrm{D}$ ) and only three students used purely cosmetic lens with zero power, whereas in other studies, cosmetic CL with zero power was used. ${ }^{47,49}$

The awareness of CL-related complications is low among young generation and $87 \%$ of them still prefer to wear CL despite of having CL-related problems. ${ }^{50,51}$ The awareness of CL complications in our study is still insufficient. Although all students knew at least one of CLrelated complications, only $40.77 \%$ of them recognized severe complication of CL-related corneal ulcers. Only 17 students $(5.06 \%)$ reported having eye check-up both before and after wearing CL. Several studies showed that significant portion of students would not visit eye doctors and continue wearing their lens. ${ }^{25}$ Importance of regular eye check-up should be emphasized in young CL wearers.

The limitation of this study was a nature of online survey, which might result in bias data due to no random sampling and low response rate. This survey was taken from the two selected Rajabhat universities, therefore our findings might not be an accurate representative of general population of university students elsewhere. Some important factors associated with poor CL behaviors including age group, study fields (medical vs non-medical), socioeconomics and CL type cannot be assessed due to the homogenous profile of population in the current study. We did not use frequency scale and no question assessed rub and rinse techniques in our survey questionnaires. Standardized questionnaire covering all aspects of CL behavior and knowledge should be developed as a consensus. Our study used self-report of hygiene and complications which were prone to be underreported. However, severe complication of corneal ulcer is unlikely to be neglected, therefore our estimates on this item should be valid.

In summary, this study indicated that Thai Rajabhat University students had inadequate CL wear and care behavior. Purchasing lenses from the internet, experienced $\mathrm{CL}$ wearers and long wearing time per day were associated with poor CL behaviors. Whereas, male gender, using tap water for cleaning or rinsing lenses and swimming with lenses were associated with higher risk of having history of CL-related corneal ulcer. We have provided the public health organizations with the information which might lead to development of safer health care policy for CL users. Good CL practices, awareness of CL-related complications and place of purchase should be carefully explained to all beginners and regularly stressed in experienced CL wearers to minimize preventable visual damages in young population.

\section{Acknowledgments}

We thank administrative staffs and lecturers from Sunandha Rajabhat and Suan Dusit University for their assistance with data collection. We also thank Ms. Sranya Phaisawang for language editing and proofreading.

\section{Disclosures}

The authors declare that they have no conflicts of interest for this work.

\section{References}

1. Konne NM, Collier SA, Spangler J, Cope JR. Healthy contact lens behaviors communicated by eye care providers and recalled by patients - United States, 2018. MMWR Morb Mortal Wkly Rep. 2019;68(32):693-697. doi:10.15585/mmwr.mm6832a2

2. Bui TH, Cavanagh HD, Robertson DM. Patient compliance during contact lens wear: perceptions, awareness, and behavior. Eye Contact Lens. 2010;36(6):334-339. doi:10.1097/ICL.0b013e3181f579f7

3. Wu Y, Carnt N, Stapleton F. Contact lens user profile, attitudes and level of compliance to lens care. Cont Lens Anterior Eye. 2010;33 (4):183-188. doi:10.1016/j.clae.2010.02.002

4. Efron N, Morgan PB, Woods CA; Consortium TICLPS. Survey of contact lens prescribing to infants, children, and teenagers. Optom Vis Sci. 2011;88(4):461-468. doi:10.1097/OPX.0b013e31820efa0f

5. Dart JK, Radford CF, Minassian D, Verma S, Stapleton F. Risk factors for microbial keratitis with contemporary contact lenses: a case-control study. Ophthalmology. 2008;115(10):1647-54, 54.e1-3. doi:10.1016/j. ophtha.2008.05.003

6. Donshik PC, Ehlers WH, Anderson LD, Suchecki JK. Strategies to better engage, educate, and empower patient compliance and safe lens wear: compliance: what we know, what we do not know, and what we need to know. Eye Contact Lens. 2007;33(6):430-433. doi:10.1097/ ICL.0b013e318157f62a

7. Lim CHL, Stapleton F, Mehta JS. Review of contact lens-related complications. Eye Contact Lens. 2018;44:S1-S10. doi:10.1097/ ICL.0000000000000481 
8. Brown AC, Ross J, Jones DB, et al. Risk factors for Acanthamoeba keratitis-a Multistate Case-Control Study, 2008-2011. Eye Contact Lens. 2018;44:S173-S8. doi:10.1097/ICL.0000000000000365

9. Butcko V, McMahon TT, Joslin CE, Jones L. Microbial keratitis and the role of rub and rinsing. Eye Contact Lens. 2007;33(6):421-423. doi:10.1097/ICL.0b013e318157f3df

10. Carnt N, Stapleton F. Strategies for the prevention of contact lens-related Acanthamoeba keratitis: a review. Ophthalmic Physiol Opt. 2016;36(2):77-92. doi:10.1111/opo.12271

11. Stapleton F, Keay L, Edwards K, et al. The incidence of contact lens-related microbial keratitis in Australia. Ophthalmology. 2008;115(10):1655-1662. doi:10.1016/j.ophtha.2008.04.002

12. Claydon BE, Efron N. Non-compliance in contact lens wear. Ophthalmic Physiol Opt. 1994;14(4):356-364. doi:10.1111/j.14751313.1994.tb00125.x

13. Wagner H, Richdale K, Mitchell GL, et al. Age, behavior, environment, and health factors in the soft contact lens risk survey. Optom Vis Sci. 2014;91(3):252-261. doi:10.1097/OPX.0000000000000164

14. Sokol JL, Mier MG, Bloom S, Asbell PA. A study of patient compliance in a contact lens-wearing population. CLAO j. 1990;16 (3):209-213.

15. Chun MW, Weissman BA. Compliance in contact lens care. Am J Optom Physiol Opt. 1987;64(4):274-276. doi:10.1097/00006324198704000-00008

16. Lam JS, Tan G, Tan DT, Mehta JS. Demographics and behaviour of patients with contact lens-related infectious keratitis in singapore. Ann Acad Med Singap. 2013;42(10):499-506.

17. Green M, Sara S, Hughes I, Apel A, Stapleton F. Trends in contact lens microbial keratitis 1999 to 2015: a retrospective clinical review. Clin Exp Ophthalmol. 2019;47(6):726-732. doi:10.1111/ceo.13484

18. Leeamornsiri S, Titawattanakul Y. Comparative knowledge and behavior of contact lens care between medical and non-medical students. J Med Assoc Thai. 2015;98:S16-S23.

19. Mahittikorn A, Kittichathanakul T, To-Im J, Nacapunchai D. Knowledge, behavior, and free-living amoebae contamination of cosmetic contact lens among university wearers in Thailand: a Cross-Sectional Study. Eye Contact Lens. 2017;43(2):81-88. doi:10.1097/ICL.0000000000000246

20. Wu YT, Willcox M, Zhu H, Stapleton F. Contact lens hygiene compliance and lens case contamination: a review. Cont Lens Anterior Eye. 2015;38(5):307-316. doi:10.1016/j.clae.2015.04.007

21. Coopersmith L, Weinstock FJ. Current recommendations and practice regarding soft lens replacement and disinfection. CLAO j. 1997;23 (3):172-176

22. Carnt N, Keay L, Willcox M, Evans V, Stapleton F. Higher risk taking propensity of contact lens wearers is associated with less compliance. Cont Lens Anterior Eye. 2011;34(5):202-206. doi:10.1016/j.clae.2010.10.004

23. Steinemann TL, Fletcher M, Bonny AE, et al. Over-the-counter decorative contact lenses: cosmetic or medical devices? A case series. Eye Contact Lens. 2005;31(5):194-200. doi:10.1097/01. icl.0000175654.79591.03

24. Radford CF, Woodward EG, Stapleton F. Contact lens hygiene compliance in a university population. Cont Lens Anterior Eye. 1993;16 (3):105-111.

25. Tajunisah I, Ophth M, Reddy SC, Phuah SJ. Knowledge and practice of contact lens wear and care among medical students of University of Malaya. Med J Malaysia. 2008;63(3):207-210.

26. Chavan WM, Giri PA, Phalke DB, Bangal SV. Knowledge and practice of contact lens wear and care among contact lens users medical students of rural medical college, Loni, Maharashtra, India. Int Biol Med Res. 2012;3(1):1385-1387.

27. Davidson SI, Akingbehin T. Compliance in ophthalmology. Trans Ophthalmol Soc UK. 1980;100(2):286-290.

28. Baker-Schena L. Patient adherence. EyeNet Magazine. 2017. Available from: https:/www.aao.org/eyenet/article/patient-adherence.
29. Cook PA, Bellis MA. Knowing the risk: relationships between risk behaviour and health knowledge. Public Health. 2001;115(1):54-61. doi:10.1038/sj/ph/1900728

30. Yildiz EH, Airiani S, Hammersmith KM, et al. Trends in contact lens-related corneal ulcers at a tertiary referral center. Cornea. 2012;31(10):1097-1102. doi:10.1097/ICO.0b013e318221cee0

31. Jongkhajornpong P, Nimworaphan J, Lekhanont K, Chuckpaiwong V, Rattanasiri S. Predicting factors and prediction model for discriminating between fungal infection and bacterial infection in severe microbial keratitis. PLoS One. 2019;14(3):e0214076. doi:10.1371/ journal.pone.0214076

32. Bamahfouz AY, Nafady-Hego H, Jouhargy S, et al. Awareness of contact lens care among college students in Saudi Arabia. Int $J$ Sci Study. 2016;4(1):90-96.

33. Lim CH, Carnt NA, Farook M, et al. Risk factors for contact lens-related microbial keratitis in Singapore. Eye (Lond). 2016;30 (3):447-455. doi:10.1038/eye.2015.250

34. Dart JK, Stapleton F, Minassian D. Contact lenses and other risk factors in microbial keratitis. Lancet. 1991;338(8768):650-653. doi:10.1016/0140-6736(91)91231-I

35. Poggio EC, Glynn RJ, Schein OD, et al. The incidence of ulcerative keratitis among users of daily-wear and extended-wear soft contact lenses. $N$ Engl J Med. 1989;321(12):779-783. doi:10.1056/ NEJM198909213211202

36. Zimmerman AB, Richdale K, Mitchell GL, et al. Water exposure is a common risk behavior among soft and gas-permeable contact lens wearers. Cornea. 2017;36(8):995-1001. doi:10.1097/ICO.00000000 00001204

37. Arshad M, Carnt N, Tan J, Ekkeshis I, Stapleton F. Water exposure and the risk of contact lens-related disease. Cornea. 2019;38 (6):791-797. doi:10.1097/ICO.0000000000001898

38. Choo J, Vuu K, Bergenske P, Burnham K, Smythe J, Caroline P. Bacterial populations on silicone hydrogel and hydrogel contact lenses after swimming in a chlorinated pool. Optom Vis Sci. 2005;82(2):134-137. doi:10.1097/01.OPX.0000153168.54495.DA

39. Caskey S, Stirling J, Moore JE, Rendall JC. Occurrence of Pseudomonas aeruginosa in waters: implications for patients with cystic fibrosis (CF). Lett Appl Microbiol. 2018;66(6):537-541. doi:10.1111/lam.12876

40. Shoff ME, Rogerson A, Kessler K, Schatz S, Seal DV. Prevalence of Acanthamoeba and other naked amoebae in South Florida domestic water. J Water Health. 2008;6(1):99-104. doi:10.2166/wh.2007.014

41. Radford CF, Minassian DC, Dart JK. Acanthamoeba keratitis in England and Wales: incidence, outcome, and risk factors. $\mathrm{Br}$ J Ophthalmol. 2002;86(5):536-542. doi:10.1136/bjo.86.5.536

42. Legarreta JE, Nau AC, Dhaliwal DK. Acanthamoeba keratitis associated with tap water use during contact lens cleaning: manufacturer guidelines need to change. Eye Contact Lens. 2013;39(2):158-161. doi:10.1097/ICL.0b013e31827a79ee

43. Jeong HJ, Lee SJ, Kim JH, et al. Acanthamoeba: keratopathogenicity of isolates from domestic tap water in Korea. Exp Parasitol. 2007;117(4):357-367.

44. Kilvington S, Gray T, Dart J, et al. Acanthamoeba keratitis: the role of domestic tap water contamination in the United Kingdom. Invest Ophthalmol Vis Sci. 2004;45(1):165-169. doi:10.1167/iovs.03-0559

45. Tilia D, Lazon de la Jara P, Zhu H, Naduvilath TJ, Holden BA. The effect of compliance on contact lens case contamination. Optom Vis Sci. 2014;91(3):262-271. doi:10.1097/OPX.0000000000000163

46. Seal DV, Kirkness CM, Bennett HG, Peterson M. Acanthamoeba keratitis in Scotland: risk factors for contact lens wearers. Cont Lens Anterior Eye. 1999;22(2):58-68. doi:10.1016/S1367-0484(99) 80004-6

47. Singh S, Satani D, Patel A, Vhankade R. Colored cosmetic contact lenses: an unsafe trend in the younger generation. Cornea. 2012;31 (7):777-779. doi:10.1097/ICO.0b013e31823cbe9c 
48. Chan KY, Cho P, Boost M. Microbial adherence to cosmetic contact lenses. Cont Lens Anterior Eye. 2014;37(4):267-272. doi:10.1016/j. clae.2013.12.002

49. Berenson AB, Chang M, Hirth JM, Merkley KH. Use and misuse of cosmetic contact lenses among US adolescents in Southeast Texas. Adolesc Health Med Ther. 2019;10:1-6. doi:10.2147/AHMT. S196573
50. Roberts A, Kaye AE, Kaye RA, Tu K, Kaye SB. Informed consent and medical devices: the case of the contact lens. Br J Ophthalmol. 2005;89(6):782-783. doi:10.1136/bjo.2004.062315

51. Hall BJ, Jones L. Contact lens cases: the missing link in contact lens safety? Eye Contact Lens. 2010;36(2):101-105. doi:10.1097/ ICL.0b013e3181d05555

\section{Publish your work in this journal}

Clinical Ophthalmology is an international, peer-reviewed journal covering all subspecialties within ophthalmology. Key topics include: Optometry; Visual science; Pharmacology and drug therapy in eye diseases; Basic Sciences; Primary and Secondary eye care; Patient Safety and Quality of Care Improvements. This journal is indexed on PubMed

Submit your manuscript here: https://www.dovepress.com/clinical-ophthalmology-journal
Central and CAS, and is the official journal of The Society of Clinical Ophthalmology (SCO). The manuscript management system is completely online and includes a very quick and fair peer-review system, which is all easy to use. Visit http://www.dovepress.com/ testimonials.php to read real quotes from published authors. 